\title{
p38 MAPK and ERK activation by 9-cis-retinoic acid induces chemokine receptors CCR1 and CCR2 expression in human monocytic THP-1 cells
}

\author{
Jesang Ko', Chi-Young Yun ${ }^{2}$, Ji-Sook Lee ${ }^{2}$, \\ Joo-Hwan Kim ${ }^{2}$ and In Sik Kim ${ }^{3,4}$ \\ ${ }^{1}$ School of Life Sciences and Biotechnology \\ Korea University \\ Seoul 136-701, Korea \\ ${ }^{2}$ Department of Biology, College of Natural Sciences \\ Daejeon University, Daejeon 300-716, Korea \\ ${ }^{3}$ Department of Biodmedical Laboratory Science \\ School of Medicine, Eulji University \\ Daejeon 301-832, Korea \\ ${ }^{4}$ Corresponding author: Tel, 82-42-259-1753; \\ Fax, 82-42-259-1759; E-mail, orientree@eulji.ac.kr
}

Accepted 4 January 2007

Abbreviations: CCR, CC chemokine receptor; $\mathrm{Cl}$, Chemotactic index; ERK, extracellular signal-regulated kinase; MAPK, mitogen activated protein kinase

\begin{abstract}
9-cis-retinoic acid (9CRA) plays an important role in the immune response; this includes cytokine production and cell migration. We have previously demonstrated that 9CRA increases expression of chemokine receptors CCR1 and CCR2 in human monocytes. To better understand how 9CRA induces CCR1 and CCR2 expression, we examined the contribution of signaling proteins in human monocytic THP-1 cells. The mRNA and surface protein up-regulation of CCR1 and CCR2 in 9CRA-stimulated cells were weakly blocked by the pretreatment of SB202190, a p38 MAPK inhibitor, and PD98059, an upstream ERK inhibitor. Activation of p38 MAPK and ERK1/2 was induced in both a time and dose-dependent manner after 9CRA stimulation. Both p38 MAPK and ERK1/2 phosphorylation peaked at $2 \mathrm{~h}$ after a $100 \mathrm{nM}$ 9CRA treatment. 9CRA increased calcium influx and chemotactic activity in response to CCR1-dependent chemokines, Lkn-1/CCL15, MIP-1 $\alpha / C C L 3$, and RANTES/ CCL5, and the CCR2-specific chemokine, MCP-1/ CCL2. Both SB202190 and PD98059 pretreatment diminished the increased calcium mobilization and chemotactic ability due to 9CRA. SB202190 inhibited the expression and functional activities of CCR1 and
\end{abstract}

CCR2 more effectively than did PD98059. Therefore, our results demonstrate that 9CRA transduces the signal through p38 MAPK and ERK1/2 for CCR1 and CCR2 up-regulation, and may regulate the pro-inflam matory process through the p38 MAPK and ERKdependent signaling pathways.

Keywords: chemotaxis; extracellular signal-regulated MAP kinases; monocytes; p38 mitogen-activated protein kinases; receptors, chemokine; retinoids

\section{Introduction}

Retinoic acid (RA), a natural derivative of vitamin A has biological effects on cell growth, differentiation and development (Evans, 1988). RA also functions as an important regulator that coordinates a variety of immune responses (Stephensen, 2001). There are two major RA stereoisomers, 9-cis-retinoic acid (9CRA) and all-trans retinoic acid (ATRA). 9CRA binds both the retinoic acid receptor (RAR) and the retinoid $X$ receptor (RXR) but ATRA binds only the RAR receptor. After interacting with $R A$, retinoid receptors preferentially form RXR/RAR heterodimers, although they may form RAR/RAR or RXR/ RXR homodimers (Stephensen, 2001). These receptors function as transcription factors and negative regulators, which control expression of the RA-response or related genes. IL-2 expression is inhibited by RA in the T cell leukemia line (Felli et al., 1991). RA binds to c-Jun after interacting with RAR, and results in the inhibition of AP-1 binding to the AP-1responsive element (Zhou et al., 1999). Other mechanisms by which RA can regulate gene expression may be related to direct protein-protein interaction with signal molecules, which is not associated with transcription factors. It has been recently reported that RA activates signaling molecules without increased expression of them (Bost et al., 2002; Antonyak et al., 2003; Teruel et al., 2003). Activation of the ERK pathway, induced by RA, is needed for differentiation of embryonic stem cells and inhibition of tissue transglutaminase expression; RA has also been shown to mediate the signal of uncoupling protein-1 (UCP-1) up-regulation, through the p38 MAPK-dependent pathway.

Interaction of chemokines with chemokine receptors plays an important role in leukocyte movement 
under the influence of inflammatory diseases and physiological immune responses such as cell growth and differentiation. Chemokine receptors are part of a large family of seven transmembrane $G$ proteincoupled receptors; they are classified into two major chemokine receptors, CC chemokine receptor (CCR) and $\mathrm{CXC}$ chemokine receptor, depending on the chemokines that bind to them (Baggiolini et al., 1997; Rollins, 1997; Luster, 1998). Both CCR1 and CCR2 are expressed in human monocytes, lymphocytes and eosinophils. Alternation of CCR1 and CCR2 expression, depending on the states of cell activation, is associated with a variety of inflammatory diseases including: multiple sclerosis, bronchial hyper-reactivity, and atopy (Campbell et al., 1999; Trebst et al., 2001; Phillips et al., 2003). Regulatory mechanism of CCR1 and CCR2 expression is required for a variety of signal transduction pathways. CCR1 expression is elevated by IFN- $\gamma$ and IFN- $\alpha$ in human monocytes (Zella et al., 1998, 1999). IL-10 enhances GM-CSF-induced CCR1 expression via activation of PKB/Akt and p70 ${ }^{\text {s6k }}$ (Li et al., 2003). Both p38 MAPK and ERK activation by LPS is required for down-regulation of CCR1 and CCR2 expression in these cells (Parker et al., 2004).

Although our recent studies have demonstrated that 9CRA increases expression of CCR 1 and CCR2, in human monocytes, the exact mechanism by which CCR1 and CCR2 up-regulation occurs is not well understood (Kim et al., 2004). Therefore, in this study, we investigated the signaling molecules required for CCR1 and CCR2 up-regulation due to 9CRA.

\section{Materials and Methods}

\section{Materials and cell culture}

RPMI 1640, FBS, and Trizol were purchased from Life Technologies, Inc. (Gaithersburg, MD). 9CRA, rat tail collagen type I and FITC-conjugated rabbit anti-mouse $\operatorname{lgG}$ were obtained from Sigma (St. Louis, MO). PD98059 and SB202190 were products of Calbiochem (San Diego, CA). Recombinant human Lkn-1/CCL15, MIP-1 $/$ /CCL3, RANTES/CCL5, MCP-1/CCL2, anti-CCR1 antibodies, and anti-CCR2 antibodies were obtained from R\&D Systems (Minneapolis, MN). Anti-phospho-ERK1/2, anti-phosphop38, and anti-p38 antibodies were obtained from Cell Signaling Technology (Beverly, MA). Anti-ERK2 antibodies were obtained from Santa Cruz Biotechnology (Santa Cruz, CA). Fluo3- acetoxymethyl (fluo3-AM) ester and pluronic F-127 were purchased from Molecular Probes (Eugene, OR). Human THP1 cells were obtained from the American Type Culture Collection (Manassas, VA) and were grown in RPMI 1640 supplemented with 10\% heat-inactivated
FBS, penicillin $(100 \mathrm{U} / \mathrm{ml})$, and streptomycin (100 $\mu \mathrm{g} / \mathrm{ml})$.

\section{Semi-quantitative RT-PCR}

RT-PCR was performed to determine relative quantities of mRNAs for CCR1 and CCR2 in 9CRAstimulated THP-1 cells. Total RNA was extracted from the cells using Trizol reagent as described in the manufacturer's instructions. For cDNA preparation, total RNA $(2 \mu \mathrm{g})$ was incubated at $37^{\circ} \mathrm{C}$ for 90 min using the first-strand CDNA synthesis kit (Promega, Madison, WI). The cDNAs were denatured at $94^{\circ} \mathrm{C}$ for $5 \mathrm{~min}$ and then amplified by 30 cycles of denaturation at $94^{\circ} \mathrm{C}$ for $1 \mathrm{~min}$, annealing at $58^{\circ} \mathrm{C}$ for $1 \mathrm{~min}$, extension at $72^{\circ} \mathrm{C}$ for $1 \mathrm{~min}$, and a final extension at $72^{\circ} \mathrm{C}$ for $10 \mathrm{~min}$. Primers used in this study were as follows: CCR1 (forward primer 5'CTCTTCCTGTTCACGCTTCC-3' and reverse primer 5'-CCAAATGTCTGCTCTGCTCA-3': 595 bp), CCR2 (forward primer 5'-AACTCCTGCCTCCGCTCTAC-3' and reverse primer 5'-TCACTGCCCTATGCCTCTTC-3': 600 bp), GAPDH (forward primer 5'-ACCACAGTCCATGCCATCAC-3' and reverse primer 5'-TCCACCACCCTGTTGCTGTA-3': 450 bp). GAPDH was used as an internal control for each $P C R$ reaction. Final PCR products were separated on $1 \%$ agarose gels and then visualized by ethidium bromide staining.

\section{Flow cytometry}

Human THP- 1 cells seeded into 6 well plates at $5 \times$ $10^{5}$ cells/well were cultured in RPMI 1640. After treatment with 9CRA, the cells were harvested and washed with PBS buffer containing $0.5 \%$ BSA. Nonspecific antibody binding was reduced by incubating the cells with normal rabbit lgG. The cells were separated into new tubes and each tube was added with PBS buffer containing anti-CCR1 or anti-CCR2 antibodies. Baseline fluorescence was obtained by incubation with normal mouse lgG instead of antichemokine receptor antibodies. After washing 3 times, the cells were incubated at $4{ }^{\circ} \mathrm{C}$ for $30 \mathrm{~min}$ with FITC-conjugated goat anti-mouse $\lg$ G. Finally, the cells were washed and analyzed on a FACSort cytofluorimeter (Becton Dickinson, Franklin Lakes, NJ). Ten thousand events were collected for each experiment. The mean intensity of untreated cells was considered as $100 \%$. Alteration of CCR1 or CCR2 surface expression after 9CRA treatment was evaluated as the mean intensity of 9CRA-treated cells/ mean intensity of untreated cells $\times 100$.

\section{Western blot analysis}

Cell extracts were prepared by homogenization in 
lysis buffer (10 mM HEPES, $10 \mathrm{mM} \mathrm{NaCl}, 0.1 \mathrm{mM}$ EDTA, 0.1 mM EGTA, 1\% NP-40, 0.5 mM PMSF, 0.1 $\mathrm{mM}$ DTT, $0.1 \mathrm{mM} \mathrm{Na}_{3} \mathrm{VO}_{4}$, and protease inhibitors). Protein samples $(30 \mu \mathrm{g} /$ well) were separated by SDSPAGE (10\%) and transferred to nitrocellulose membranes. The blots were incubated with anti-phospho-ERK1/2, or anti-phospho-p38 antibodies, and developed with the enhanced chemiluminescence detection system (Amersham Pharmacia Biotech, Piscataway, NJ). The same membranes were stripped and reprobed with anti-ERK2 or anti-p38 antibodies for normalization.

\section{Measurement of intracellular $\mathrm{Ca}^{2+}$ concentration} Intracellular $\mathrm{Ca}^{2+}$ concentration was measured as previously described (Kim et al., 2005). Harvested cells were washed twice with HBSS and resuspended in HBSS containing $1 \mu \mathrm{M}$ fluo3-AM and $0.01 \%$ pluronic $\mathrm{F}-127$. After incubation for $30 \mathrm{~min}$ at $37^{\circ} \mathrm{C}$, cells were washed three times. Dye-loaded cells were resuspended in $\mathrm{Ca}^{2+}$ assay buffer (135 $\mathrm{mM} \mathrm{NaCl}, 3.6 \mathrm{mM} \mathrm{KCl}, 2.5 \mathrm{mM} \mathrm{CaCl}_{2} 2 \mathrm{H}_{2} \mathrm{O}, 10 \mathrm{mM}$ glucose, $5 \mathrm{mM}$ HEPES, $0.1 \% \mathrm{BSA}, \mathrm{pH} 7.4)$, and incubated for $30 \mathrm{~min}$ at $37^{\circ} \mathrm{C}$. Chemokines $(100 \mathrm{ng} / \mathrm{ml})$ were added, and subsequently intracellular $\mathrm{Ca}^{2+}$ con-
A

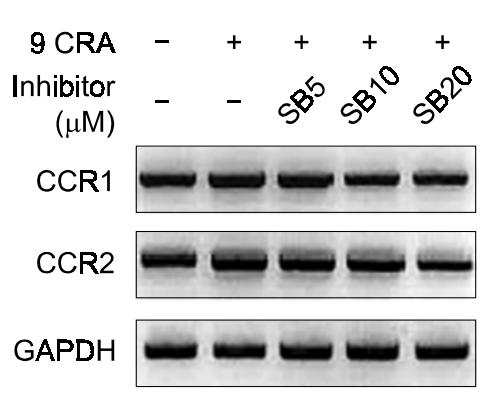

B

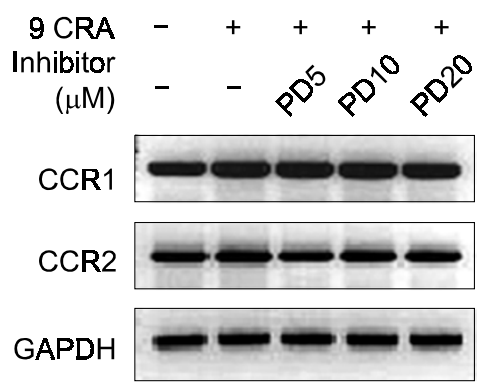

CCR1
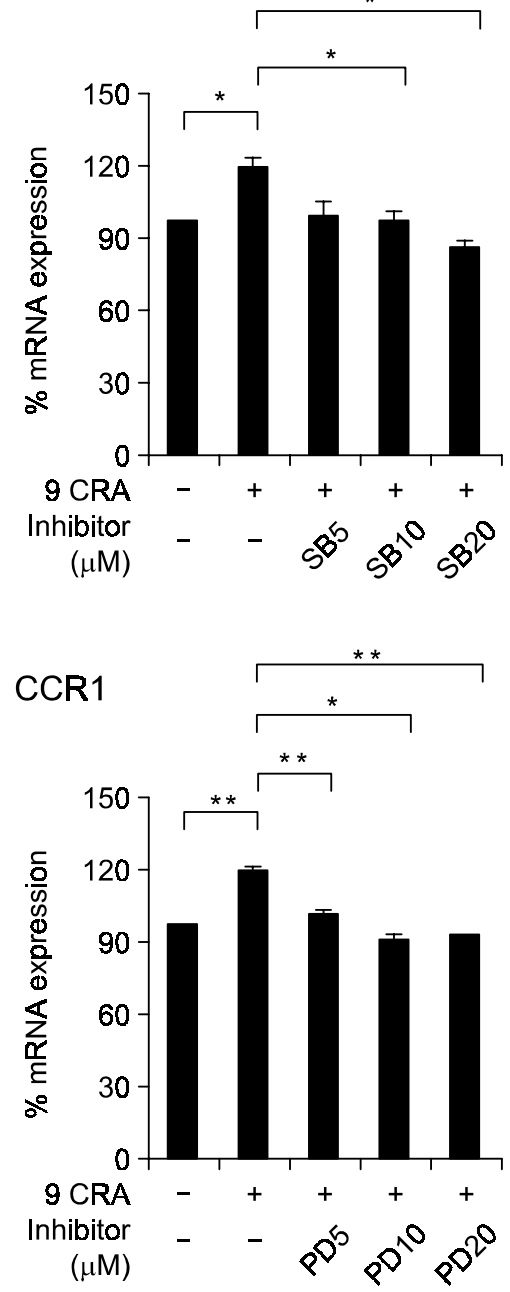
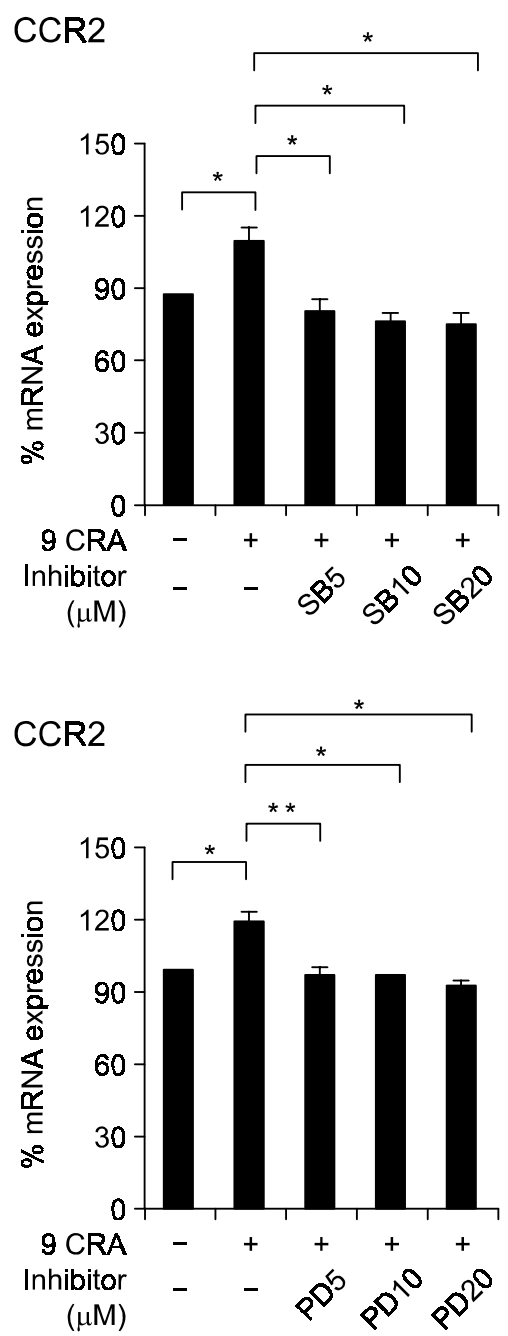

Figure 1. Both $p 38$ MAPK and ERK are involved in the CCR1 and CCR2 mRNA expression induced by 9CRA in THP-1 cells. THP-1 cells were serum starved with $0.5 \%$ serum for $24 \mathrm{~h}$. The cells were pre-treated with the indicated concentrations of SB202190 (SB5; $5 \mu \mathrm{M}, \mathrm{SB} 10$; $10 \mu \mathrm{M}, \mathrm{SB} 20$; $20 \mu \mathrm{M})(\mathrm{A})$ or PD98059 (PD5; $5 \mu \mathrm{M}, \mathrm{PD} 10 ; 10 \mu \mathrm{M}, \mathrm{PD} 20 ; 20 \mu \mathrm{M})(\mathrm{B})$, and incubated in the presence of $100 \mathrm{nM} 9 \mathrm{CRA}$ for $12 \mathrm{~h}$. Total RNA was extracted from 9CRA-treated THP-1 cells. mRNA levels of CCR1 and CCR2 were analyzed by RT-PCR using CCR1 or CCR2 primer as described in Methods. GAPDH was used as an internal control. Data are expressed as representative of three individual experiments (left panels). Densitometric analysis was performed using Quantity One software (Biorad Laboratories, Hercules, CA). Data are expressed as means \pm S.E.M. and presented in relation to negative control, which was set at $100 \%$ (right panels). ${ }^{*} P<0.05$ and ${ }^{* *} P<0.01$ were accepted as a significant difference. 
A
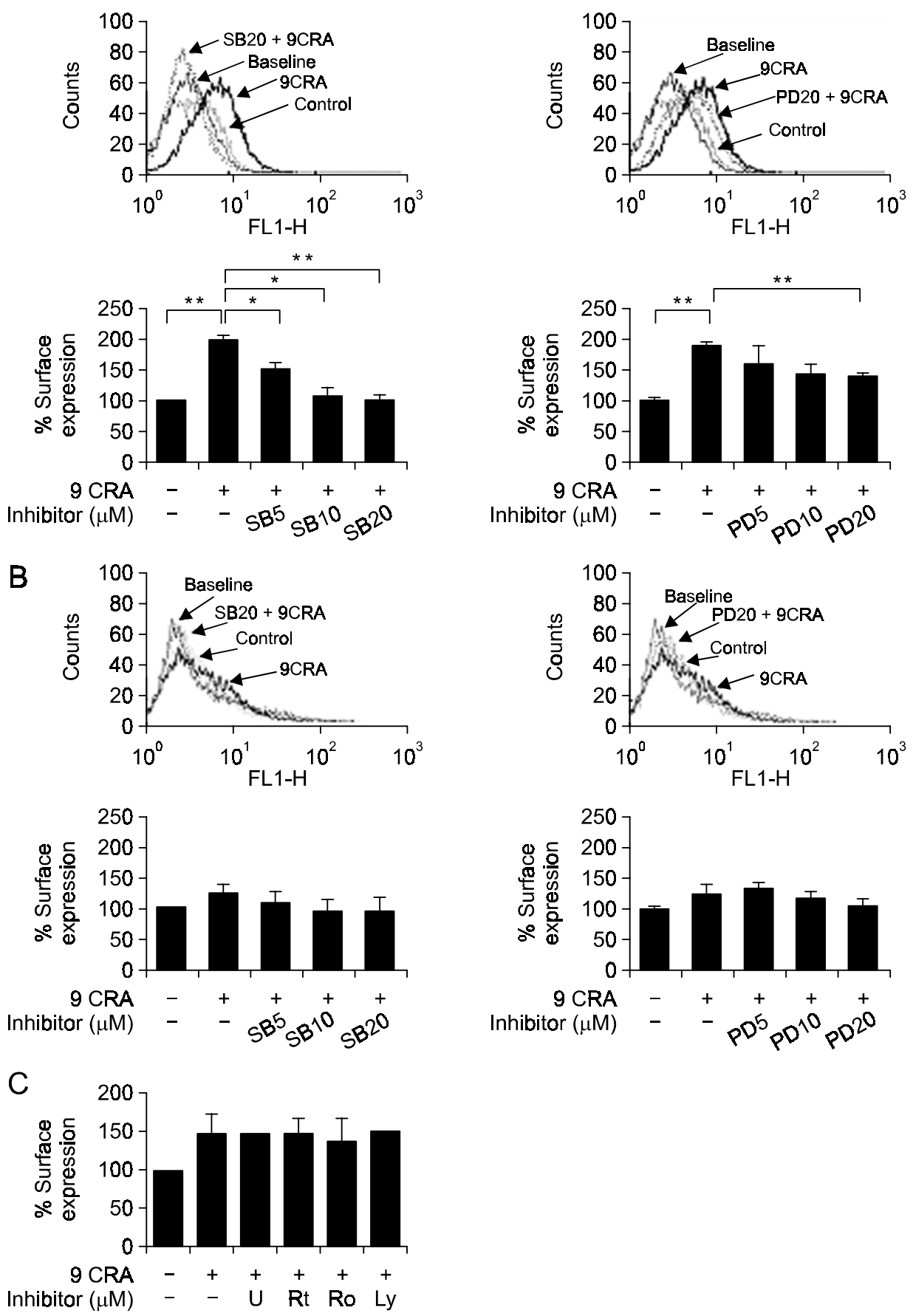

centration was analyzed at $488 \mathrm{~nm}$ of excitation wavelength and $530 \mathrm{~nm}$ of emission wavelength on a FACSort cytofluorimeter. Baseline fluorescence was monitored for $40 \mathrm{~s}$ before addition of chemokines.

\section{Chemotaxis assay}

Cell migration was performed using a 48-well micro-
Figure 2. Both SB202190 and PD98059 inhibit the surface expression of CCR1 and CCR2 induced by 9CRA in 9CRA-treated THP-1 cells. THP-1 cells were serum starved with $0.5 \%$ serum for $24 \mathrm{~h}$. The cells were pre-treated in the presence of the indicated concentrations of SB202190 (SB5; 5 $\mu \mathrm{M}, \mathrm{SB} 10 ; 10 \mu \mathrm{M}, \mathrm{SB} 20 ; 20 \mu \mathrm{M}$; long dotted line), PD98059 (PD5; 5 $\mu \mathrm{M}, \mathrm{PD} 10 ; 10 \mu \mathrm{M}, \mathrm{PD} 20 ; 20 \mu \mathrm{M}$; long dotted line), U73122 (U; 10 $\mu \mathrm{M})$, rottlerin (Rt; $10 \mu \mathrm{M})$, Ro-318425 (Ro; $100 \mathrm{nM}$ ), or Ly294002 $(\mathrm{Ly} ; 10 \mu \mathrm{M})$ and incubated in the presence of $100 \mathrm{nM}$ 9CRA for 12 $h$. The cells were harvested and analyzed by a fluorescence-activated cell sorter using monoclonal anti-CCR1 antibodies (A, C) or anti-CCR2 antibodies (B). Baseline fluorescence was obtained by incubating with normal mouse lgG (baseline; thin line). A negative control was not treated with either inhibitor or 9CRA (control; short dotted line). A positive control was treated with 9CRA but without inhibitor pre-treatment (9CRA; thick line). Data are expressed as representative of three individual experiments (upper panels of $A$ and $B$ ) or data are expressed as means \pm S.E.M. and presented in relation to negative control, which was set at $100 \%$ (lower panels of $A, B$ and $C$ ). ${ }^{*} P<0.05$ and ${ }^{* *} P<0.01$ were accepted as a significant difference. chamber (Neuroprobe, Gaithersburg, MD) as previously described. (Kim et al., 2004). The lower wells were filled with $28 \mu \mathrm{l}$ buffer alone or with buffer containing chemokine, and a polyvinylpyrrolidone-free filter (Neuroprobe) with 10 pores was placed over the lower wells. Membranes were pre-coated with RPMI 1640 containing rat tail collagen type I at $4^{\circ} \mathrm{C}$ 
overnight. The upper wells were filled with $50 \mu \mathrm{l}$ of THP- 1 cells at $2 \times 10^{6}$ cells $/ \mathrm{ml}$ in RPMI 1640 containing $1 \% \mathrm{BSA}$ and $30 \mathrm{mM}$ HEPES. The chamber was incubated for $5 \mathrm{~h}$ at $37^{\circ} \mathrm{C}$. After the polycarbonate filter was removed, cells adhering to its upper surface were wiped off with a filter wiper. A filter was dried, fixed, and stained with Diff-Quick (Baxter, McGaw Park, IL). The cells of four randomly selected fields per well were counted using the Axiovert 25 (Carl Zeiss, Jena, Germany) and the Visus Image Analysis System (Foresthill Products, Foresthill, CA). The chemotactic index $(\mathrm{Cl})$ was calculated from the number of cells that migrated to the control.

\section{Statistical analysis}

Data are expressed as means \pm S.E.M. Statistical differences were analyzed using the paired $t$-test for two-group comparisons and one-way ANOVA test for more than three group comparisions. The SPSS statistical software package (Version 10.0, Chicago, IL) was used for statistical analysis. A significant value was defined as $P<0.05$.

\section{Results}

Both p38 MAPK and ERK are involved in 9CRAinduced CCR1 and CCR2 expression in THP-1 cells

To gain insight into the molecular mechanism involved in 9CRA-induced chemokine receptor expression, we examined signaling molecules associated with this mechanism. THP-1 cells were pre-treated with SB202190, an inhibitor of p38 MAPK and PD98059, an upstream inhibitor of ERK, and incubated with $100 \mathrm{nM}$ 9CRA for $12 \mathrm{~h}$. The mRNA expression of CCR1 and CCR2 was detected by performing RT-PCR. Both inhibitors weakly blocked the increased mRNA levels of CCR1 and CCR2 due to 9CRA in a dose-dependent manner $(P<0.05)$ (Figure 1$)$.

We next investigated the surface protein expression of CCR1 and CCR2 by performing a FACS analysis. CCR1 expression was significantly inhibited by stimulation with SB202190 and PD98059 ( $P$ $<0.05)$ (Figure 2A). However, reduction of CCR2 expression was not significantly affected by both inhibitors; this is because CCR2 surface expression is little affected in response to 9CRA as previously reported (Kim et al., 2004) (Figure 2B). SB202190 inhibition was more effective than PD98059. In addition, other inhibitors including a phospholipase C inhibitor (U73122), a PI3 kinase inhibitor (Ly294002), an inhibitor of classic PKC (Ro-31-8425), and a PKC $\delta$ inhibitor (rottlerin) had no effect on the increased CCR 1 expression induced by 9CRA (Figure $2 \mathrm{C})$. These results correlate with a blocking effect of the inhibitors on CCR1 and CCR2 mRNA expression and indicate that 9CRA-induced signal pathway for CCR1 and CCR2 expression is required for p38 MAPK and ERK.

\section{CRA induces both p38 MAPK and ERK activation}

Since CCR1 and CCR2 up-regulation by 9CRA is associated with p38 MAPK and ERK, as shown by our prior results, we investigated whether 9CRA activates p38 MAPK and ERK or increases expression of both signal molecules in a time and dosedependent manner by performing Western blotting. As shown in Figure $3 \mathrm{~A}$, phosphorylation of p38 MAPK and ERK1/2 began to increase at $1 \mathrm{~h}$ after exposure of THP-1 cells to $100 \mathrm{nM}$ 9CRA, and

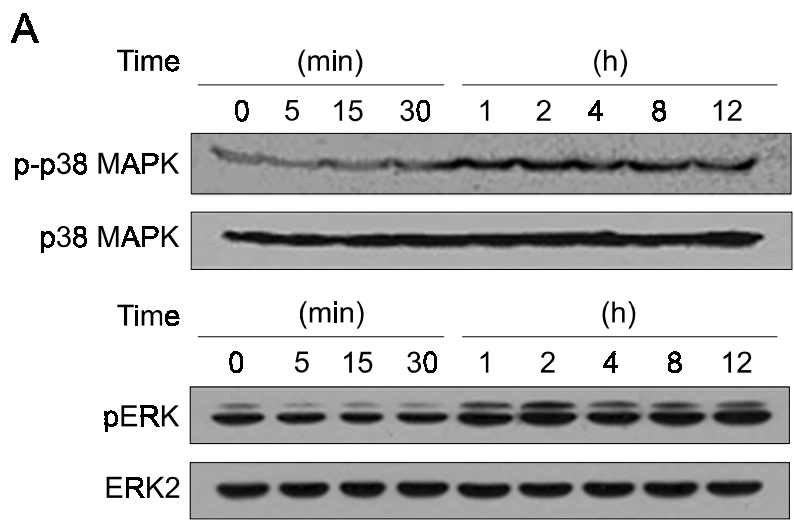

B

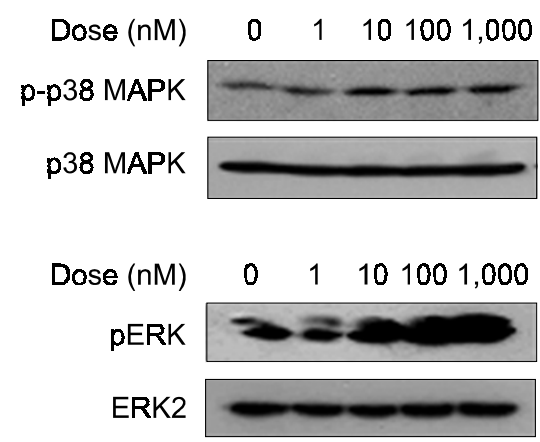

Figure 3. 9CRA induces both p38 MAPK and ERK activation. THP-1 cells were serum starved with $0.5 \%$ serum for $24 \mathrm{~h}$. The cells were incubated with $100 \mathrm{nM}$ 9CRA for the indicated time $(\mathrm{A})$ or with the described concentrations of 9 CRA for $2 \mathrm{~h}$ (B). Harvested cells were lysed and extracted proteins were separated on 10\% SDS-polyacrylamide gels $(50 \mu \mathrm{g} / \mathrm{lane})$ and transferred to nitrocellulose membrane. Activation of p38 MAPK and ERK were detected by Western blotting with anti-phospho p38 MAPK and anti-phospho ERK antibodies, respectively. The membrane was stripped and reprobed with p38 MAPK and ERK2 antibodies as an internal control. 
A

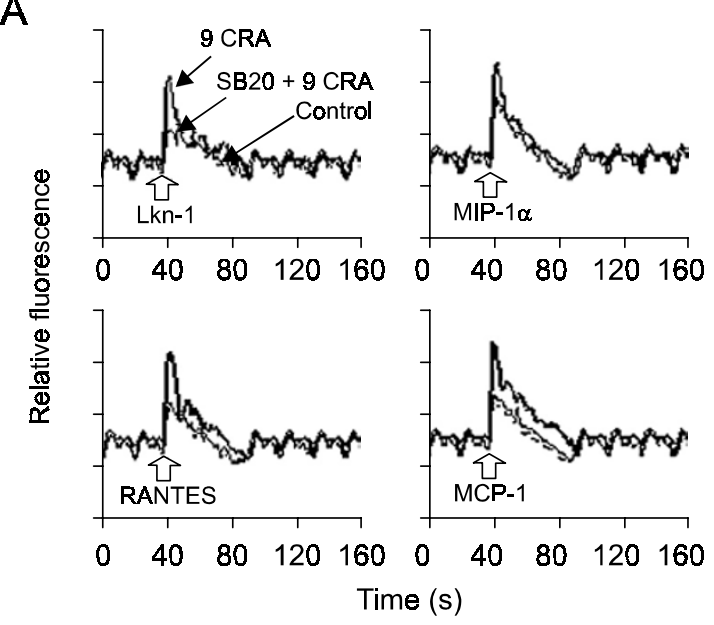

B

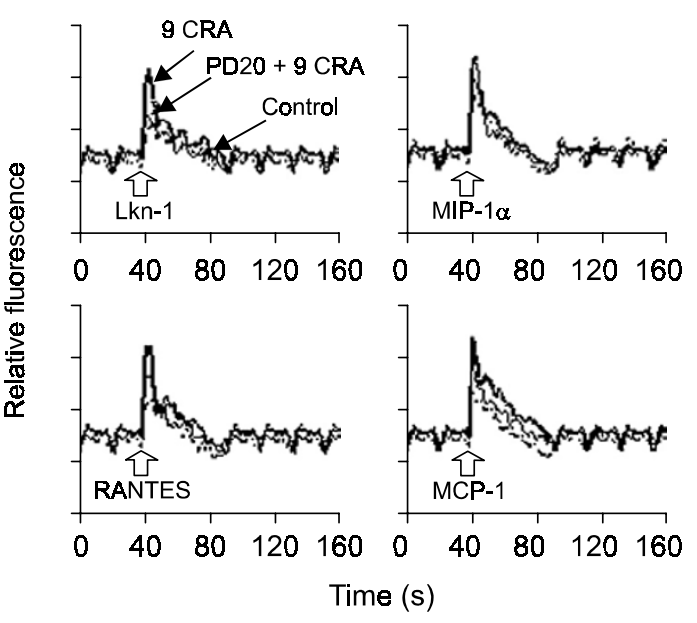

C

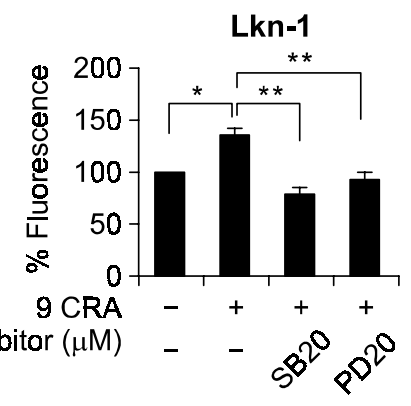

RANTES

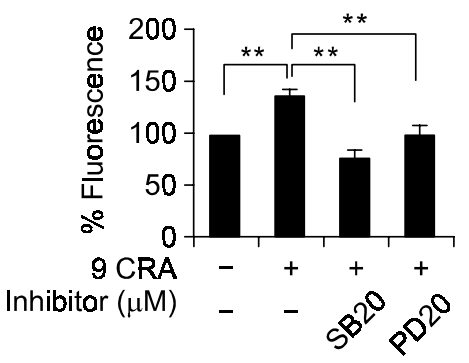

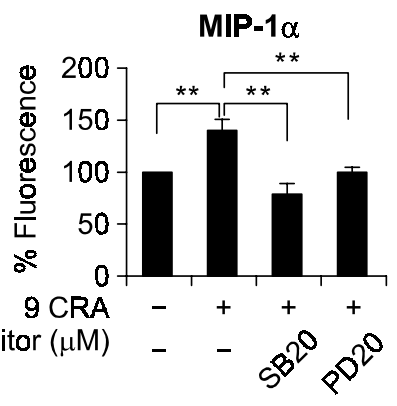

MCP-1

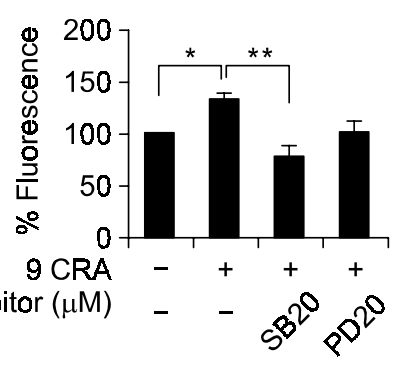

Figure 4. $\mathrm{Ca}^{2+}$ mobilization in response to CCR1 and CCR2-dependent chemokines is inhibited by SB202190 and PD98059 in 9CRA-treated THP-1 cells. Serum starved THP-1 cells were pre-treated in the presence of $20 \mu \mathrm{M} \mathrm{SB202190} \mathrm{(A,} \mathrm{SB20;} \mathrm{thin} \mathrm{line)} \mathrm{or} \mathrm{PD98059} \mathrm{(B,} \mathrm{PD20;} \mathrm{thin} \mathrm{line)} \mathrm{and} \mathrm{in-}$ cubated in the presence of $100 \mathrm{nM}$ 9CRA for $24 \mathrm{~h}$ (9CRA), then loaded with fluo3-AM. Dye-loaded cells were stimulated with the indicated chemokines $(200 \mathrm{ng} / \mathrm{ml})$, and subsequently monitored for $120 \mathrm{~s}$. A negative control was not treated with either inhibitor or 9CRA (control; dotted line). A positive control was treated with 9CRA but without inhibitor pre-treatment (9CRA; thick line). Data are expressed as representative of three independent experiments $(A, B)$ or data are expressed as means \pm S.E.M. and presented in relation to the negative control, which was set at $100 \%(C)$. ${ }^{*} P<$ 0.05 and ${ }^{* *} P<0.01$ were accepted as a significant difference.

reached a maximum level at $2 \mathrm{~h}$. The activation decreased gradually after the peak time, but it was sustained for up to $12 \mathrm{~h}$. In dose dependent experiments, THP-1 cells were treated with a variety of concentrations of 9CRA for $2 \mathrm{~h}$. Both p38 MAPK and ERK phosphorylation started to increase at $10 \mathrm{nM}$ and were maintained up to $1,000 \mathrm{nM} 9 \mathrm{CRA}$ (Figure 3B). Un-phosphorylated expression of p38 and ERK2 was not affected by 9CRA.

\section{$\mathrm{Ca}^{2+}$ mobilization in response to CCR1 and CCR2-dependent chemokines is inhibited by SB202190 and PD98059 in 9CRA-treated THP-1 cells}

To confirm the regulatory role of the signal pathway involved in P38 MAPK and ERK, we evaluated the 
inhibitory effect of SB202190 and PD98059 on calcium mobilization in response to CCR1 and CCR2specific chemokines enhanced by 9CRA. THP-1 cells were pre-treated in the absence or presence of both inhibitors and incubated with 9CRA. After stimulation with the CCR1-dependent chemokines, Lkn-1, MIP-1 $\alpha$ and RANTES, or the CCR2-specific chemokine, MCP-1, the intracellular $\mathrm{Ca}^{2+}$ concentration was measured by a $\mathrm{Ca}^{2+}$ influx assay. As shown in Figure 4, $\mathrm{Ca}^{2+}$ mobilization into 9CRA-treated THP-1 cells was significantly increased by the CCR1-dependent chemokines as well as the CCR2-specific chemokine. SB202190 completely blocked the increased calcium concentration in response to CCR1 and CCR2-dependent chemokines (Figure $4 A$ and $C$ ), and PD98059 partially inhibited it (Figure 4B and C). These results correlate with the data from CCR1 and CCR2 expression blocked by both inhibitors.

\section{Both SB202190 and PD98059 inhibited chemotactic activity in response to CCR1 and CCR2-dependent chemokines in 9CRA-treated THP-1 cells}

Cell migration in response to a chemokine is enhanced by increased chemokine receptor. We confirmed the inhibitory effect of SB202190 and PD98059
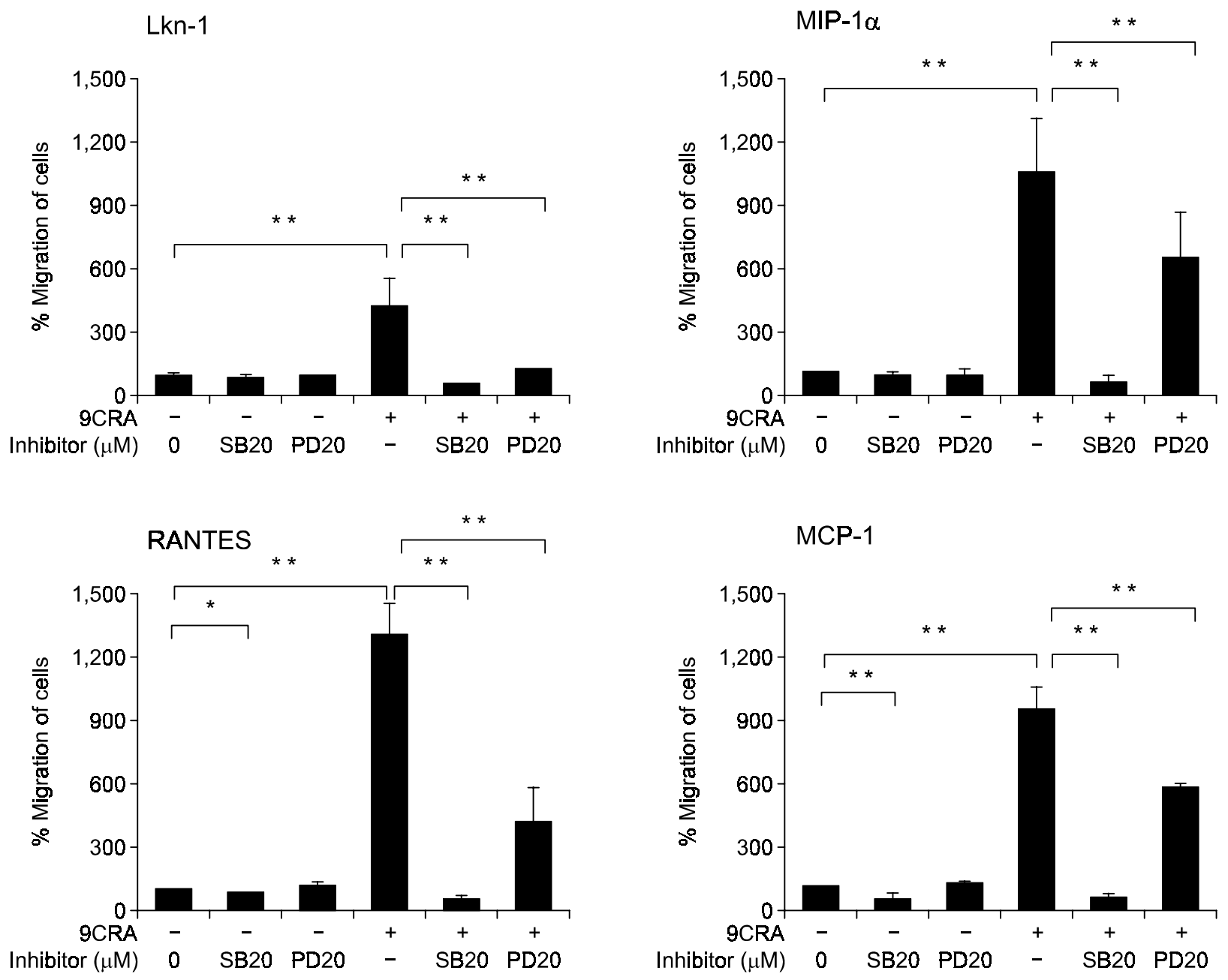

Figure 5. Both SB202190 and PD98059 inhibit chemotactic activity in response to CCR1 and CCR2-dependent chemokines in 9CRA-treated THP-1 cells. THP-1 cells were pre-treated in the absence or presence of $20 \mu \mathrm{M}$ SB202190 (SB20) or PD98059 (PD20) and incubated in the absence or

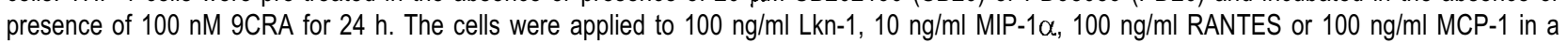
48-well microchamber and were allowed to migrate for $5 \mathrm{~h}$. Filters were stained with Diff-Quick. The number of cells that migrated was counted microscopically in two randomly selected fields per well. Six replicate measurements are included in a single experiment. Data are expressed as means \pm S.E.M. of four independent experiments, and presented in relation to the negative control, which was set at $100 \%$. ${ }^{*} P<0.05$ and ${ }^{* *} P<0.01$ were accepted as a significant difference. 
on increased chemokine receptor expression after 9CRA treatment. SB202190 and PD98059 pretreatment significantly decreased cell migration in response to Lkn-1, MIP-1 $\alpha$, RANTES, and MCP-1 in 9CRA-treated THP-1 cells, despite the different blocking effect of both inhibitors on chemotactic activity in response to each chemokine $(P<0.01)$ (Figure $5)$. In addition, the basal level of THP-1 cell migration in response to RANTES and MCP-1 was significantly inhibited by SB202190 but not by PD98059 $(P<0.05)$ (Figure 5). These results demonstrate that p38 MAPK mediates the chemotaxis signal elicited by RANTES and MCP-1 as well as chemokine receptor expression due to 9CRA.

\section{Discussion}

In the present study, we investigated the signaling molecules involved in the expression of CCR1 and CCR2 due to 9CRA in human monocytic THP-1 cells. We demonstrated that (1) both p38 MAPK and ERK are involved in the mRNA and surface expression of CCR1 and CCR2 due to 9CRA, (2) 9CRA induces phosphorylation of p38 MAPK and ERK1/2 in both a time and dose-dependent manner, (3) 9CRA enhances calcium influx and cell migration in response to CCR1 and CCR2-dependent chemokines, resulting from CCR1 and CCR2 up-regulation via p38 MAPK and ERK1/2 activation, and (4) p38 MAPK transduces the chemotaxis signal elicited by CCR1-dependent chemokine, RANTES and CCR2dependent chemokine, MCP-1.

To examine the molecular mechanism associated with CCR 1 and CCR2 expression induced by 9CRA, we used pharmacologic inhibitors of signaling molecules. Our results showed that SB202190 markedly inhibited the protein up-regulation of CCR1 induced by 9CRA, and resulted in recovery of the basal level of CCR1 expression (Figure 2). PD98059 partially reversed the up-regulation. However, other signaling inhibitors had no effect on expression of chemokine receptor induced by 9CRA (Figure 2C). These results suggest that p38 MAPK and ERKdependent pathways are required for CCR1 or CCR2 up-regulation induced by 9CRA.

The action of RA is mediated via nuclear receptors. After binding to a nuclear receptor, RA can directly bind to the promoters of targeted genes, and then enhance transcription and translation. Recently, studies have demonstrated that RA induces activation of MAPK and PI3 kinase in different cell models, despite the fact that the precise mechanism by which RA induces these pathways remains to be determined (Bost et al., 2002; Antonyak et al., 2003; Teruel et al., 2003). Our results showed that RA ac- tivates both p38 MAPK and ERK1/2 in a dose and time-dependent manner (Figure 3 ), resulting in the up-regulation of CCR1 and CCR2 expression. To explain how 9CRA activates MAPK, we considered several possible mechanisms: (1) 9CRA or 9CRA/ $\mathrm{RXR}$ complex directly interacts with the signaling proteins, (2) 9CRA increases expression of p38 and ERK, and (3) 9CRA decreases activity or expression of MAPK phosphatase. Since 9CRA, a lipophilic molecule, freely diffuses across plasma membranes, direct MAPK activation by 9CRA would be rapidly induced. Most of the MAPK phosphorylation by extracellular ligands are elicited within 30 min (Feoktistov et al., 1999; Kim et al., 2003). Our results show that both p38 MAPK and ERK phosphorylation peaked at $2 \mathrm{~h}$ after treatment with $100 \mathrm{nM}$ 9CRA. The peak time after activation was not observed to be a short time after 9CRA treatment. In addition, basal expression of p38 MAPK and ERK was not altered by 9CRA treatment. Therefore, this hypothesis is very unlikely. Although we have not found the precise MAPK-dependent signal pathway, our results indicate that 9CRA enhances the expression of chemokine receptors through complex mechanisms; this may include the activation of upstream molecules of p38 MAPK and ERK, as well as increased activation of transcription factor or coactivator of the retinoid receptor by activated p38 MAPK and ERK1/2. Further investigations are now required, and our laboratory is currently pursuing this area of study.

Both p38 MAPK and ERK1/2 act as positive regulators for CCR1 and CCR2 up-regulation due to 9CRA. SB202190 completely blocked the CCR1 and CCR2 up-regulation, and this resulted in complete inhibition of cell migration and calcium influx in response to CCR1 and CCR2-dependent chemokines enhanced by 9CRA (Figure 4 and 5). In comparision with the effect of SB202190, PD98059 induced a weak blocking effect on expression of both receptors and their functional activities. Therefore, p38 MAPK may be considered as the main signaling protein mediating the pathway involved in expression of chemokine receptors. The results from prolonged ERK1/2 activation after 9CRA treatment indicate that ERK plays the role of an assistant on the expression of chemokine receptors, rather than inducing other biological effects due to 9CRA including cell differentiation and modulation of the cell cycle as demonstrated in previous reports (Hong et al., 2001; Yen et al., 2004).

p38 MAPK plays an important role in the chemotactic activity of monocytes (Ashida et al., 2001; Cambien et al., 2001). As shown in Figure 5, our results show that p38 MAPK mediates the chemotaxis signal in response to CCR1 and CCR2-dependent chemokines. SB202190 significantly dimini- 
shed the cell migration induced by the CCR1-dependent chemokine, RANTES, and the CCR2-dependent chemokine, MCP-1, but not by other CCR1depednent chemokines, Lkn-1 and MIP-1 $\alpha$. This result suggests that p38 MAPK is involved in a differential CCR1-mediated chemotaxis signal in monocytes as we have previously reported. (Kim et al., 2005) Therefore, p38 MAPK may function as a key molecule in the inflammatory response of monocytes; this is because it is involved in the regulatory mechanism of CCR expression following cell activation as well as the chemotaxis signal pathway induced by chemokines, which are essential for evoking inflammation.

In summary, we demonstrated that 9CRA increases both CCR1 and CCR2 expression through the p38 MAPK and the ERK-dependent pathways. These results demonstrate the first evidence of p38 MAPK and ERK activation induced by 9CRA in human monocytes. This study may help elucidate the regulatory mechanism involved in the pro-inflammatory effect of 9CRA.

\section{Acknowledgment}

This work was supported by RIC(R) grants from Traditional and Bio-Medical Research Center, Daejeon University (RRC04730, 2005) by ITEP.

\section{References}

Antonyak MA, McNeill CJ, Wakshlag JJ, Boehm JE, Cerione RA. Activation of the Ras-ERK pathway inhibits retinoic acid-induced stimulation of tissue transglutaminase expression in NIH3T3 cells. J Bio Chem 2003;278:15859-66

Ashida N, Arai H, Yamasaki M, Kita T. Distinct signaling pathways for MCP-1-dependent integrin activation and chemotaxis. J Bio Chem 2001;276:16555-60

Baggiolini M, Dewald B, Moser B. Human chemokines: an update. Annu Rev Immunol 1997;15:675-705

Bost F, Caron L, Marchetti I, Dani C, Le Marchand-Brustel Y, Binetruy $B$. Retinoic acid activation of the ERK pathway is required for embryonic stem cell commitment into the adipocyte lineage. Biochem J 2002;361:621-27

Cambien B, Pomeranz M, Millet MA, Rossi B, Schmid-Alliana A. Signal transduction involved in MCP-1-mediated monocytic transendothelial migration. Blood 2001;97:359-66

Campbell EM, Charo IF, Kunkel SL, Strieter RM, Boring L, Gosling J, Lukacs NW. Monocyte chemoattractant protein-1 mediates cockroach allergen-induced bronchial hyperreactivity in normal but not CCR2 $2^{-/-}$mice: the role of mast cells. J Immunol 1999;63:2160-7

Evans RM. The steroid and thyroid hormone receptor superfamily. Science 1988;240:889-95

Felli MP, Vacca A, Meco D, Screpanti I, Farina AR, Maroder
M, Martinotti S, Petrangeli E, Frati L, Gulino A. Retinoic acid-induced down-regulation of the interleukin-2 promoter via cis-regulatory sequences containing an octamer motif. Mol Cell Biol 1991;11:4771-8

Feoktistov I, Goldstein AE, Biaggioni I. Role of p38 mitogenactivated protein kinase and extracellular signal-regulated protein kinase kinase in adenosine $\mathrm{A} 2 \mathrm{~B}$ receptor-mediated interleukin-8 production in human mast cells. Mol Pharmacol 1999;55:726-34

Hong HY, Varvayanis S, Yen A. Retinoic acid causes MEK-dependent RAF phosphorylation through RARalpha plus RXR activation in HL-60 cells. Differentiation 2001;68:55-66

Kim IS, Ryang YS, Kim YS, Jang SW, Sung HJ, Lee YH, Kim $\mathrm{J}$, Na DS, Ko J. Leukotactin-1-induced ERK activation is mediated via Gi/Go protein/PLC/PKC delta/Ras cascades in HOS cells. Life Sci 2003;73:447-59

Kim IS, Kim YS, Jang SW, Sung HJ, Han KH, Na DS, Ko J. Differential effects of 9-cis retinoic acid on expression of CC chemokine receptors in human monocytes. Biochem Pharmacol 2004;68:611-20

Kim IS, Jang SW, Sung HJ, Lee JS, Ko J. Differential CCR1mediated chemotaxis signaling induced by human $\mathrm{CC}$ chemokine HCC-4/CCL16 in HOS cells. FEBS Lett 2005;579:6044-8

Li H, Cheung W, Choo HH, Chan JH, Lai PS, Fred Wong WS. IL-10 synergistically enhances GM-CSF-induced CCR1 expression in myelomonocytic cells. Biochem Biophys Res Commun 2003;304:417-24

Luster AD. Mechanisms of disease: chemokines-chemotactic cytokines that mediate inflammation. N Eng J Med 1998; 338:436-45

Parker LC, Whyte MK, Vogel SN, Dower SK, Sabroe I. Toll-like receptor (TLR)2 and TLR4 agonists regulate CCR expression in human monocytic cells. J Immunol 2004;172:4977-86

Phillips RM, Stubbs VE, Henson MR, Williams TJ, Pease JE, Sabroe I. Variations in eosinophil chemokine responses: an investigation of CCR1 and CCR3 function, expression in atopy, and identification of a functional CCR1 promoter. J Immunol 2003;170:6190-201

\section{Rollins BJ. Chemokines. Blood 1997;90:909-28}

Stephensen CB, Vitamin A. infection, and immune function. Annu Rev Nutr 2001;21:167-92

Teruel T, Hernandez R, Benito M, Lorenzo M. Rosiglitazone and retinoic acid induce uncoupling protein-1 (UCP-1) in a p38 mitogen-activated protein kinase-dependent manner in fetal primary brown adipocytes. J Biol Chem 2003;278:263-9

Trebst C, Sorensen TL, Kivisakk P, Cathcart MK, Hesselgesser J, Horuk R, Sellebjerg F, Lassmann H, Ransohoff RM. CCR1+/CCR5+ mononuclear phagocytes accumulate in the central nervous system of patients with multiple sclerosis. Am J Pathol 2001;159:1701-10

Yen A, Fenning R, Chandraratna R, Walker P, Varvayanis S. $A$ retinoic acid receptor beta/gamma-selective prodrug (tazarotene) plus a retinoid $X$ receptor ligand induces extracellular signal-regulated kinase activation, retinoblastoma hypophosphorylation, G0 arrest, and cell differentiation. Mol Phar- 


\section{macol 2004;66:1727-37}

Zella D, Barabitskaja O, Burns JM, Romerio F, Dunn DE, Revello MG, Gerna G, Reitz MS Jr. Gallo RC, Weichold FF. Interferon- $\gamma$ increases expression of chemokine receptors CCR1, CCR3, and CCR5, but not CXCR4 in monocytoid U937 cells. Blood 1998;91:4444-50

Zella D, Barabitskaja O, Casareto L, Romerio F, Secchiero P,
Reitz MS Jr. Gallo RC, Weichold FF. Recombinant IFN- $\alpha$ (2b) increases the expression of apoptosis receptor CD95 and chemokine receptors CCR1 and CCR3 in monocytoid cells. J Immunol 1999;163:3169-75

Zhou XF, Shen XQ, Shemshedini L. Ligand-activated retinoic acid receptor inhibits AP-1 transactivation by disrupting c-Jun/c-Fos dimerization. Mol Endocrinol 1999;13:276-85 